\title{
Influence of cultural contexts on the appreciation of different cultural ecosystem services based on social network analysis
}

\author{
Francisca Mutwa Kilonzi ${ }^{\ddagger}$, Takahiro Ota ${ }^{\ddagger}$ \\ ‡ Nagasaki University, Nagasaki, Japan
}

\section{Corresponding author: Francisca Mutwa Kilonzi (franciscakarem@gmail.com)}

Academic editor: Joerg Priess

Received: 25 Jan 2019 | Accepted: 19 Mar 2019 | Published: 27 Mar 2019

Citation: Kilonzi F, Ota T (2019) Influence of cultural contexts on the appreciation of different cultural ecosystem services based on social network analysis. One Ecosystem 4: e33368. https://doi.org/10.3897/oneeco.4.e33368

\begin{abstract}
Since the Millennium Ecosystem Assessment, ecosystem science domain has made tremendous progress in the study of ecosystem services, but debates on neglected cultural ecosystem services (CES) have persisted. A recent approach established by the Intergovernmental Panel for Biodiversity and Ecosystem Services (IPBES) identifies and advocates incorporation of the CES through the role of local knowledge across other ecosystem services. However, approaches and tools that enable engagement of CES are limited. In this study, we examine how cultural contexts influence the appreciation of different CES, by identifying the behavioural aspects and the indigenous knowledge that has evolved on the basis of Social Network Analysis (SNA). SNA measures the network of relations between people and groups developed traditionally for a long time and their relational values with natural resources and ecosystem services. Through a comprehensive literature review of scholarly research published in Scopus data base, this study explicitly illustrates the interrelationship between SNA and CES. Keywords associated with SNA and cultural ecosystem services including forests, fisheries and agriculture (farming) were used. It was found that various aspects of social network uphold relational values of cultural importance and enhance resilience in groups amidst the social changes and times as societies progress. For instance, in the case of homophily, actors who are attracted to one another chose to interact in their defined network (e.g. fishing
\end{abstract}


network) forming a strong social capital. Consequently, they shared similar beliefs and values that were eventually handed to the next generation of the network which shaped their heritage and identity. Social learning networks in various communities were also found to play a key role in information exchange and knowledge sharing among members compared to information from foreign technical experts. To fully integrate CES into sustainable decision making, this review suggests incorporation of the analysis of social networks formed in different cultural contexts globally.

\section{Keywords}

Social network analysis, cultural ecosystem services, cultural contexts, IPBES

\section{Introduction}

There are numerous scientific interrelationships between human and nature that have been studied in terms of concepts and methods. In the recent past, Millennium ecosystem services (MEA) has been widely studied and dominated in both natural and social sciences (MEA 2005). From the assessment, the largest part of literature focuses mainly on the provisioning and regulating services, abandoning the cultural ecosystem services (Rosa et al. 2016, Small et al. 2017, Costanza et al. 2017, Maes et al. 2018). However, provisioning and regulating services have high potential to be restored, unlike the cultural ecosystem services that have the least potential for mediation and once degraded, are unlikely to be replaced (Hernández-Morcillo et al. 2013, Chan et al. 2016). The recent global studies indicated that human dependence on cultural ecosystem services increased in the course of a country's economic development, while dependence on provisioning ecosystem services decreased (Hernández-Morcillo et al. 2013). For example, a broad stakeholder survey conducted in the Puget Sound region of Washington State, found that recreation, tourism, ethical and existence values (cultural ecosystem services) were recurrently reported as among the five most important ecosystem services (Iceland et al. 2008, Kreitler et al. 2013).

Despite their importance, it has become very difficult to fully integrate cultural ecosystem services in ecosystem services framework assessment and into decision-making (Chan et al. 2012, Satz et al. 2013, Díaz et al. 2018, Jones et al. 2016). This inability is due to lack of recognition of the role of material objects in the provisioning of the non-material benefits and their complex interactions among human and non-human areas (Bryce et al. 2016, Ungaro et al. 2016). Nevertheless, cultural ecosystem services have emerged as a central concept to the understanding of ecosystem's life enriching and affirming contributions to human well-being where culture is embraced as an important variable in the ecosystem assessment (Díaz et al. 2018, Fish et al. 2016).

To incorporate the cultural ecosystem services developed in the previous approaches including the MEA (2005), TEEB (2010) and the Global Biodiversity Assessment (GBA) 
(Hengeveld and Heywood 1996), a recent approach was established by the Intergovernmental Panel for Biodiversity and Ecosystem Services (IPBES) (IPBES 2016). The IPBES approach resonates with the MEA classification however, it goes further to embrace the concepts associated with world-views on human-nature relations, indigenous cultures and diverse values (Pascual et al. 2017). The nature's contributions to people (NCP) classification includes the material, non-material and regulating contributions, within which 18 more sub-categories are included (IPBES 2016, Díaz et al. 2018). The material contributions directly sustain people's physical existence such as food and water; nonmaterial contributions are nature's effects on subjective or psychological aspects underpinning people's quality of life individually or collectively such as recreation, whereas regulating contributions indirectly affect the quality of life (Díaz et al. 2018). These three categories have been acknowledged to explicitly overlap, with culture (cultural ecosystem services) permeating across all the categories (Díaz et al. 2015). Together with the Convention on Biological Diversity (CBD) developed in 2010 (CBD 2010), IPBES strongly acknowledges the importance of cultural ecosystem services through the indigenous and local knowledge and support the role of diversity of knowledge systems in international biodiversity assessments as well as in decision-making (IPBES 2013, Tengö et al. 2014).

However, tools and approaches to engage the local knowledge from all the involved stakeholders are still limited (Tengö et al. 2014, Tengö et al. 2017, Whyte et al. 2015). In this article, we aim to understand and engage cultural ecosystem services in a Social Network Analysis (SNA) perspective in different cultural contexts. Social network analysis has its roots in several theoretical perspectives such as the sociometry developed by Moreno in 1934, in which interpersonal relations were presented pictorially (Xerez 2013). Others have traced the approach to the work of British anthropologist John Barnes in 1954, Elizabeth Bott in 1957, Clyde Mitchell in 1969 and others as an outgrowth of Claude LeviStrauss, a French structuralism in 1969 (Freeman 2004). Whereas differences exist among the many approaches, most sociologists agree that social network analysis is founded on the social relations on behavioural patterns of individuals or groups (Mizruchi 1994).

Social network analysis, as a tool, measures the network of relations between people and institutions that are linked to natural resources and ecosystem services (Prell et al. 2010). By analysing the network, one can understand how a society contributes to the management of natural resources and how communities take actions in protecting the ecosystem and the ecosystem services. Additionally, through the close-knit networks, actors communicate and share knowledge and stories that are handed from one group of generation to another. The stories reveal rich evidence regarding connections to identity, heritage, inspiration, aesthetic values and recreation which are core aspects of cultural ecosystem services (Chan et al. 2012, MEA 2005).

Engagement of a society is important for their indigenous knowledge as they live in, own and manage vast lands often rich in biodiversity and critical ecosystem services (Pascual et al. 2017, Tengö et al. 2017). Moreover, humans are inseparable component of the world's ecosystem and their actions influence all the ecosystem services (Chan et al. 2016). Their relationships, actions, beliefs and communication patterns form the social network (Coleman 1990). We focus on the relational values and the local knowledge 
created and expressed through interactions with various ecosystems and ecosystem services including forests, fishing/fisheries and agriculture (farming). Relational values are the preferences, principles, and virtues associated with relationships, as articulated by policies and social norms and are often intertwined with cultural ecosystem services (AriasArévalo et al. 2017, Chan et al. 2016, Pascual et al. 2017). Hence, SNA presents a powerful tool for understanding the relational values and indigenous as well as local knowledge that provide different world-views attributed to specific cultures (Brown and Fagerholm 2015).

This study therefore, reports how cultural contexts influence the appreciation of different cultural ecosystem services, by identifying the behavioural aspects and the indigenous knowledge developed, based on social network analysis. The paper is organised in two main parts - the method part introduces the selection criteria of the articles used in this review, whereas results and discussion section gives findings of the study. Social network analysis aspects such as tie strength, homophily, centrality density, centralization and trust, and the various cultural contexts are discussed with case-study examples. The conclusion part gives the summary of the study.

\section{Methodology}

Publication content review analysis was conducted in January 2019, from literature found in Scopus database. We chose Scopus as the primary data source as it is the largest global database of published documents. A list of peer-reviewed research documents was generated using search combinations of keywords that are associated with SNA and CES including forests (natural beauty, tourism), fisheries and agriculture (as cultural heritage) as shown in Table 1 (Bodin et al. 2006). The initial search yielded a total of 240, 176 and 41 documents selected from the three broad fields of fisheries, forestry and agriculture, respectively. The second step was the exclusion of non-relevant articles based on abstracts with careful screening for similar acronyms to SNA, such as system of national accounts (SNA) (Goio et al. 2008) and specific needle area (SNA) (Shi et al. 2013). A total of 102 articles were selected from the Scopus for further analysis following the steps shown in Fig. 1. The resulting literature ( $n=37$ Suppl. material 1$)$ was then systematically reviewed to identify the interrelationship between social network aspects and various cultural ecosystem services represented in different cultural contexts globally.

\section{Table 1.}

Keyword for the search from the Scopus database

\begin{tabular}{|l|l|l|}
\hline Search & Terminologies used & Search results \\
\hline $1^{\text {st }}$ search & Social Network Analysis (SNA), Fisheries, Cultural ecosystem services & 240 \\
\hline $2^{\text {nd }}$ search & Social Network Analysis (SNA), Forestry, Cultural ecosystem services & 176 \\
\hline $3^{\text {rd }}$ search & Social Network Analysis (SNA), Agriculture, Cultural ecosystem services & 41 \\
\hline
\end{tabular}




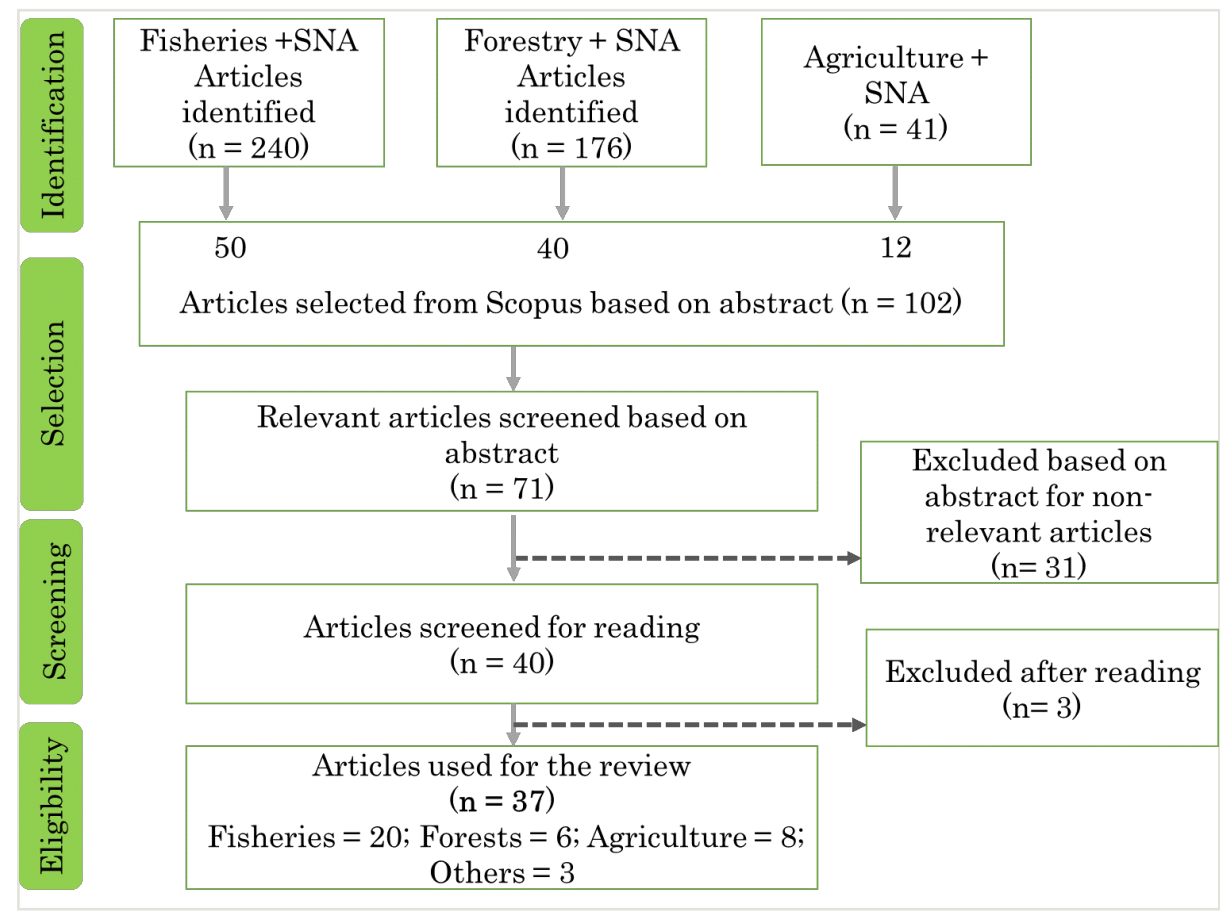

Figure 1.

Articles' selection eligibility process.

\section{Results and Discussion}

The results were analysed based on various cultural contexts depicted in the major areas including fishing, forestry and agriculture (farming) that provide opportunities for various contributions to people (cultural ecosystem services in our case), such as recreation, inspiration, identity among others. As shown in Fig. 2, the fishing category recorded the highest number of publications (54\%), followed by agriculture $(16 \%)$ and forests $(16 \%)$. Selected examples were drawn to explicitly illustrate how these cultural contexts influence the appreciation of different cultural ecosystem services, through participation of daily life activities in specific networks, such as fishing or farming that mostly rely on local knowledge and skills.

In this section, we discuss in detail the social network analysis aspects: tie strength, homophily, centrality, density, power and influence; and how, through cultural contexts, they influence the appreciation of different cultural ecosystem services.

Tie strength is a combination of the amount of time, emotional intensity, mutual confiding and reciprocal services which characterise the tie (Mertens et al. 2015). Actors sharing strong ties influence one another, share similar views, communicate effectively regarding 
complex information and trust one another (Wellman and Frank 2001, Crona and Bodin 2006). These ties can either be:

1. Bonding which refers to relations among family members, close friends and neighbours in a closed network or

2. Bridging ties, that link one network to another and facilitate access to information and resources that exist in one network to the other (Newman and Dale 2006).

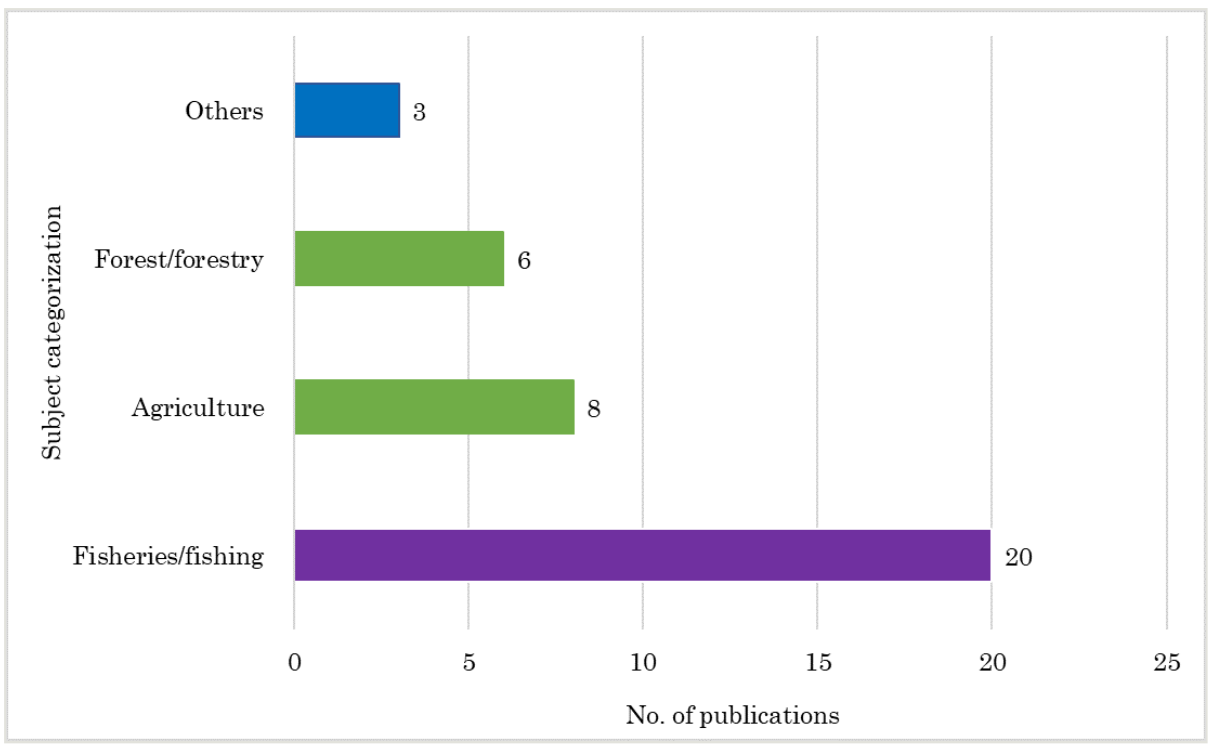

Figure 2.

Number of publications per specific subject category.

Combination of both bridging and bonding ties in a network results to social capital. Therefore, strong social capital is good for communication, to hold and maintain trust between actors and to encourage creation and maintenance of norms. These aspects of strong ties make cultural ecosystem services easily understood and trusted by other outside parties, for instance, scientists and conservationists. Weak ties, on the other hand, can lead to poor understanding of cultural ecosystem services due to lack of trust that can distort or discontinue important cultural heritage practices and norms since they (weak ties) are easy to break (Reed et al. 2009). Chan et al. 2012 explains that people/society cannot be exempted from the ecosystem services due to their intangible benefits. The author gives an example of fishers and their emotional attachment to the coastal areas or the identity and sense of belonging, derived from ownership of a boat and a fishing licence as an important cultural ecosystem service. This sense of belonging to the coastal area and ownership is passed by the fishing family from generation to generation and eventually becomes a sense of identity to the society with its surrounding network. Through the tie strength, these kinds of traits are shared and maintained throughout the network and become part of their social and economic features. Moreover, Bieling 2014 carried out a 
survey by collecting stories of the residents around Swabian Alb biosphere in southwestern Germany, to examine their mention on cultural ecosystem services. From his research, $74 \%$ of the topics of the told stories addressed identity, $64 \%$ of the topics related to recreation, $57 \%$ of the topics on aesthetic values, heritage aspects were $50 \%$ of the topics, $21 \%$ pointed to inspiration derived from the landscape, while $14 \%$ about ethical dimensions or spiritual/religious values attached to the Swabian Alb region (Bieling 2014). As portrayed in these stories, cultural ecosystem services result from the interplay between human perception, valuation and specific landscape features.

Homophily is a situation where similar actors are attracted to one another and hence choose to interact with each other in their defined network (Ruef et al. 2003, Newman and Dale 2006, Prell et al. 2010). Individuals who are similar to one another are attracted to each other, have more mutual understanding and, thus, can communicate implicit knowledge easily (Raymond et al. 2010). This social attraction leads to individuals forming a tie with one another (Prell et al. 2010). Through knowledge exchange, cultural ecosystem services are preserved, utilised and passed from one individual to another. Homophily enhances resilience in a group. Therefore, amidst the social changes and times as societies progress, cultural heritage values can be maintained. A good example of homophily that has resulted in preservation and protection of cultural heritage is the Maasai community in Kenya. Despite the cultural erosion and influence by the modern (western) lifestyle, the Maasai people have maintained their culture and heritage for a very long time. Originally nomadic, the life of Maasai has for long been communally interwoven with their natural surroundings (Bussmann et al. 2006). Their close-knit ties have encouraged passage of valuable cultural information from one generation to another that has ultimately become a source of attraction to the tourists visiting Maasai Mara national park.

Centrality reflects the relative importance of individual actors in a network (Kim et al. 2010). An actor's central position in a social network has a significant impact on others' behaviour and well-being (Brass et al. 2004). A highly centralised network is characterised by relatively few individuals holding most ties with the rest of the individuals in the network. Centralised networks are helpful for the initial phase of forming groups and building support for collective actions (Reed et al. 2009). There are various forms of centralities including the degree of centrality which refers to how many other actors to whom a stakeholder is directly connected to (Crona and Bodin 2006). In relation to cultural context, if a stakeholder/actor has a high degree of centrality, it means that she/he has larger influence and can spread the information to a wider group. These persons are important in information sharing and bringing actors together, hence preservation of information. "Betweenness", another form of centrality, refers to how many times an actor interacts between two others who are themselves disconnected (Freeman 1978). Such actors play a brokerage role bringing together disconnected groups back to the network (Brass et al. 2004, Bodin et al. 2006). This can be important in safeguarding the cultural ecosystem services within the network and connecting people in different ecosystems that eventually preserve the cultural ecosystem services. For instance, a study, conducted in agrobiodiversity ecosystems in the Andes of central Bolivia, illustrates the linkage between the existing social network structure and cultural landscape that influences the use and the 
type of food cultivated (Zimmerer 2014, Fischer et al. 2016). Moreover, the authors acknowledge the role of cultural landscapes knowledge in conserving the local agroecosystems despite the global changes and migration.

We also examined the role of centralization or the position of individuals in the network in learning new cultural knowledge and expertise. Social network analysis provides information on the position of individual actors in the networks, such as core or periphery. Core actors are located at the centre of the network. They are usually key members of the community with developed dense connections (Cattani and Ferriani 2008). Individuals at the core are deeply entrenched in the social system and therefore tend to more closely share ideas and habits. In contrast, peripheral individuals in the network are located at the periphery with minimal influence in the overall network (Cattani and Ferriani 2008). However, studies have shown that peripheral actors are better situated to integrate otherwise unconnected actors, support access to and integration of new knowledge (Yamaki 2017, Ernstson et al. 2009). Peripheral actors are often sources of new information due to their heterogeneity, an important attribute in natural resource management (Angst et al. 2018). Indeed, the position of an individual in the social network partially predicts his or her knowledge and expertise (Díaz et al. 2018), whereby, core individuals with very high centrality tend to hold more knowledge than the less central people (Díaz-Reviriego et al. 2016, Hopkins 2011). Here, we illustrate how the network position in a cultural context influences the appreciation of cultural ecosystem services, by focusing on some selected case studies: A study carried out in Yucatan, Mexico illustrates the role of individual positions in the network in learning and acquiring of traditional ecological knowledge. It was found that people in Tabi who were older and more centralised in the network had higher competence in herbal remedies compared to the less centralised people (Hopkins 2011). A similar study was conducted in a fishing community among the Tsimane' Amerindians of the Bolivian amazon to assess the relationship between fishing expertise and their positions in the network (Díaz-Reviriego et al. 2016). An association between fishers' expertise and their centrality in the network, whereby people with higher centralities were rated higher than those with lesser centralities, was reported. Additionally, the role of social network centralization in appreciating fisheries resources was depicted in Northumberland lobster fishery in UK, formed as a result of demand of social process to influence the fisheries dynamics due to over-exploitation (Turner et al. 2014). Social network analysis was used to quantitatively explore the links between information sharing networks and the fishing success of four ports (Stevens et al. 2015). It was found that fishers shared information with others whom they perceived to be successful, particularly the central fishers with higher in-degree.

Close-knit and centralized social network also contribute in appreciating the cultural ecosystem services through information sharing and education between generations. In the case of Satoumi (Japanese coastal social-ecological production landscape), a study conducted by Uehara et al. 2018, to assess the effect of ocean literacy programmes at a district junior high school from the local fishermen in Hinase district, revealed that relational values are critical component for Satoumi, which has been sustained over centuries through adaptive management, as led by fishermen through the various relationships. 
Ocean literacy allows high school students to learn from stakeholders conversant in Satoumi, including the local fishermen, residents and Non-Profit Organizations (NPOs) (Uehara et al. 2018). During this learning period, the students are able to reconnect with the ocean landscape and develop sense of attachment and pride in their hometown.

In terms of social network analysis, power and influence are measured by analysing the social structure and relationships among the individuals (Bartholdson and Porro 2018, Krott et al. 2014). Individuals with higher degree (both in-degree and out-degree) have more power than the rest (Prell et al. 2010). The power and influence role is depicted in the Chilean system whereby the law recognised the role of power and influence in the organized existing artisanal fishers to regulate common-property territorial use rights and harvests of the endangered fish species (Marín and Berkes 2010). Similarly, a whole network approach was also used to investigate the role of network structure in mediating food security in a traditional fish riparian community in Tapajos river in the Brazilian amazon (Mertens et al. 2015). Social network analysis was used to map existing linkages among the fishing communities, their co-management structures and the adaptive capacities. Due to their power and influence, the fishing communities were successful in implementing co-management agreements to regulate the exploitation of floodplain lake fisheries that effectively secured productivity and conservation for the local people (Mertens et al. 2015).

Density is another social network measure that contributes to appreciation of cultural ecosystem services in different cultural contexts and landscapes. High density network contributes to the strengthening of trust between individuals and groups, and thereby increases the possibility for social control (Bodin et al. 2006). It additionally contributes to the development of, and compliance with mutual norms in relation to what is considered acceptable, promoting homogeneity (Coleman 1990). High density network develops the systemic social roles and responsibilities that all emerge from interaction with the environment, hence enriching the cultural ecosystem services. It also fosters collective action among groups where members voluntarily cooperate among themselves to address issues such as a common ecosystem management problem in a given ecosystem (Barnaud et al. 2018). According to Masterson et al. (2017), people-place relations strengthen the protective norms that are embedded in the social institutions for stewardship. The author stresses that sense of place enhances assessment of ecosystem management, such as identification of human-valued priority areas for environmental conservation and management (Plieninger et al. 2013). Place attachments produced through repeated personal experiences in social contexts facilitates stewardship by protecting the cultural values/memories gained and the emotional attachments (Masterson et al. 2017).

Moreover, it is important to note that trust, which is a shared belief that actors in a certain relationship possess similar and compatible interests (Håkansson and Witmer 2015), is an important aspect for any social network in influencing various cultural contexts towards the appreciation of cultural ecosystem services. The lack of trust in the social network goes against the vision of connecting like-minded people, as members may not feel comfortable to express their opinions and share ideas (Sherchan et al. 2013). For instance, the various 
co-operations formed to ease fishing challenges indicate the role of trust in information sharing and on the fishing co-management as well as expeditions, such as when, where and what kind of fish are available (Barnes-Mauthe et al. 2013).

As earlier mentioned, one of the objectives of IPBES is to assess and promote the local/ indigenous knowledge of the earth's biodiversity and ecosystems as well as their contributions to human societies (IPBES 2016). Cultural landscapes are central in appreciating the cultural ecosystem services through the different interactions between people and landscapes. Landscapes provide sites of importance for people's individual and collective memories and identifications (Tengberg et al. 2012). According to Daniel et al. 2012, natural or semi-natural features of the environment are often related to the identity of an individual or the whole community through experiences arising from the natural environment that are shared across generations. Social networks act as a key-holder (of the society) of the local/indigenous knowledge and contribute in information sharing that fosters group resilience and maintenance of the associated cultural values.

Therefore, engagement of the indigenous people and local communities through the cultural contexts formed within social networks is important for knowledge contribution. For instance, Mexico has a long tradition of forest resource management whereby the communities identify themselves with dominant crops such as the coffee agroforests among the ejido community (García-Amado et al. 2012). The study by García-Amado et al. 2012 found that combination of various activities such as forestry, agriculture, ecotourism among others led to development of policies for fostering community development. The established social networks contributed in achieving common knowledge aimed at conserving the agroforests upon which various farming activities relied. Participants among the ejido community stressed the importance of the knowledge and connections acquired through learning networks in capacity building among the communities despite their different cultural and geographical divides.

Similary, in Europe where agricultural landscapes are perceived to be of cultural entities from which societies extract multiple benefits (Brescancin et al. 2018, Garcia-Martin et al. 2017); farmers were mentioned as the most important actors in a study conducted by Hauck et al. 2016 using social network analysis to identify key stakeholders in agricultural biodiversity governance. The analysis revealed importance of information flow in influencing biodiversity governance. Farming activities therefore, offered avenue for knowledge dissemination, cultural identification as well as heritage, passed from one generation to another. Moreover, a study carried out by Pietri et al. 2015 shows that even in instances where socio-cultural differences exist, a shared cause such as landscape or ecosystem management and conservation or the ecosystem services use can bring people together. The study demonstrated the role of learning networks in offering tangible opportunities for peer-to-peer interactions (eg. fisherman-to-fisherman, farmer-to-farmer), as opposed to solely receiving information from technical experts (who are often foreigners) (Kocho-Schellenberg and Berkes 2015). This portrays the value and trust embedded in local social networks, compared to outside world regarding information/ knowledge sharing. 
Taken together, these case-study examples illustrate how different cultural contexts manifested through the shared values, beliefs, identities and interpretations of significant events from common experiences (e.g. agricultural landscapes/farming, fishing, forests) have significantly contributed to understanding and appreciating the cultural ecosystem services. Furthermore, these cultural contexts and landscapes provide both the material and non-material benefits to people, as well as good quality of life, whereas the social network analysis acts as a bridge to appreciate the role of cultural contexts in indigenous knowledge and information sharing.

\section{Conclusion}

IPBES recognizes that indigenous people and local community possess detailed knowledge on biodiversity and ecosystem trends, formed through their direct dependence on their local ecosystems. The acquired knowledge is adapted and enriched with time while being passed down from one generation to another mostly through the existing social networks, hence forming a rich cultural heritage and identity. In this study, we focused on the importance of different cultural contexts influencing the appreciation of cultural ecosystem services through the indigenous knowledge developed from distinct experiences. Aspects of social network such as tie strength, homophily, centrality, density, centralization, trust, information sharing, power and influence and their contributions towards appreciating cultural ecosystem services were discussed. Explicit examples were drawn from different cultural contexts including forests, fisheries/fishing and agriculture/ farming in various regions globally. It was found that social network aspects uphold relational values of cultural importance and enhance resilience in groups amidst social changes and times as societies progress. Social learning networks in various communities were found to play a key role in information exchange and knowledge sharing among members compared to information obtained from foreign technical experts. Therefore, to fully integrate cultural ecosystem services into sustainable decision-making, we propose the analysis of social networks formed in different cultural contexts globally.

\section{Acknowledgements}

This publication was supported by JSPS KAKENHI Grant Number JP16K00692 and JP18K11731. Author FMK acknowledges the PhD scholarship received from Ministry of Education, Culture, Sports, Science and Technology, Japan (MEXT) for studies at Nagasaki University.

\section{Hosting institution}

School of Fisheries and Environmental Science, Nagasaki University. 


\section{Author contributions}

F.M.K carried out the review and wrote the manuscript, T.O contributed to the development of the research theme.

\section{Conflicts of interest}

None.

\section{References}

- $\quad$ Angst M, Widmer A, Fischer M, Ingold K (2018) Connectors and coordinators in natural resource governance: insights from Swiss water supply. Ecology and Society 23 (2). https://doi.org/10.5751/es-10030-230201

- $\quad$ Arias-Arévalo P, Martín-López B, Gómez-Baggethun E (2017) Exploring intrinsic, instrumental, and relational values for sustainable management of social-ecological systems. Ecology and Society 22 (4): 43. https://doi.org/10.5751/es-09812-220443

- $\quad$ Barnaud C, Corbera E, Muradian R, Salliou N, Sirami C, Vialatte A, Choisis J, Dendoncker N, Mathevet R, Moreau C, Reyes-García V, Boada M, Deconchat M, Cibien C, Garnier S, Maneja R, Antona M (2018) Ecosystem services, social interdependencies, and collective action: a conceptual framework. Ecology and Society 23 (1): 15. https://doi.org/10.5751/es-09848-230115

- $\quad$ Barnes-Mauthe M, Arita S, Allen S, Gray S, Leung P (2013) The influence of ethnic diversity on social network structure in a common-pool resource system: Implications for collaborative management. Ecology and Society 18 (1). https://doi.org/10.5751/ es-05295-180123

- $\quad$ Bartholdson Ö, Porro R (2018) Brokers - A Weapon of the Weak: The Impact of Bureaucracy and Brokers on a Community-based Forest Management Project in the Brazilian Amazon. Forum for Development Studies 46 (1): 1-22. https:// doi.org/10.1080/08039410.2018.1427621

- $\quad$ Bieling C (2014) Cultural ecosystem services as revealed through short stories from residents of the Swabian Alb (Germany). Ecosystem Services 8: 207-215. https:// doi.org/10.1016/j.ecoser.2014.04.002

- Bodin Ö, Crona B, Ernstson H (2006) Social networks in natural resource management: What is there to learn from a structural perspective? Ecology and Society 11 (2): r2. https://doi.org/10.5751/es-01808-1102r02

- $\quad$ Brass DJ, Galaskiewicz J, Greve HR (2004) Taking stock of networks and organisations: a multilevel perspective. Academy of Management Journal 47 (6): 795-817. https://doi.org/10.2307/20159624

- Brescancin F, Dobšinská Z, Meo ID, Šálka J, Paletto A (2018) Analysis of stakeholders' involvement in the implementation of the Natura 2000 network in Slovakia. Forest Policy and Economics 89: 22-30. https://doi.org/10.1016/j.forpol.2017.03.013 
- $\quad$ Brown G, Fagerholm N (2015) Empirical PPGIS/PGIS mapping of ecosystem services: A review and evaluation. Ecosystem Services 13: 119-133. https://doi.org/10.1016/ j.ecoser.2014.10.007

- $\quad$ Bryce R, Irvine K, Church A, Fish R, Ranger S, Kenter J (2016) Subjective well-being indicators for large-scale assessment of cultural ecosystem services. Ecosystem Services 21: 258-269. https://doi.org/10.1016/i.ecoser.2016.07.015

- Bussmann RW, Gilbreath GG, Solio J, Lutura M, Lutuluo R, Kunguru K, Wood N, Mathenge SG (2006) Plant use of the Maasai of Sekenani Valley, Maasai Mara, Kenya. Journal of Ethnobiology and Ethnomedicine 2: 22. https:// doi.org/10.1186/1746-4269-2-22

- $\quad$ Cattani G, Ferriani S (2008) A Core/Periphery Perspective on Individual Creative Performance: Social Networks and Cinematic Achievements in the Hollywood Film Industry. Organization Science 19 (6): 824-844. https://doi.org/10.1287/orsc.1070.0350

- CBD (2010) 1137 Convention [n] on biological diversity. In: Evert KJ, Ballard EB, Elsworth DJ, Oquiñena I, Schmerber JM, Stipe RE (Eds) Encyclopedic dictionary of landscape and urban planning. Springer, Berlin, Heidelberg pp. https://

doi.org/10.1007/978-3-540-76435-9 2617

- Chan KA, Guerry A, Balvanera P, Klain S, Satterfield T, Basurto X, Bostrom A, Chuenpagdee R, Gould R, Halpern B, Hannahs N, Levine J, Norton B, Ruckelshaus M, Russell R, Tam J, Woodside U (2012) Where are cultural and social in ecosystem Services? A framework for constructive engagement. BioScience 62 (8): 744-756. https://doi.org/10.1525/bio.2012.62.8.7

- Chan KA, Balvanera P, Benessaiah K, Chapman M, Díaz S, Gómez-Baggethun E, Gould R, Hannahs N, Jax K, Klain S, Luck G, Martín-López B, Muraca B, Norton B, Ott K, Pascual U, Satterfield T, Tadaki M, Taggart J, Turner N (2016) Opinion: Why protect nature? Rethinking values and the environment. Proceedings of the National Academy of Sciences 113 (6): 1462-1465. https://doi.org/10.1073/pnas.1525002113

- Coleman J (1990) Foundations of Social Theory. Foundations of Social Theory https:// doi.org/10.1515/9783486827262

- $\quad$ Costanza R, Groot Rd, Braat L, Kubiszewski I, Fioramonti L, Sutton P, Farber S, Grasso $M(2017)$ Twenty years of ecosystem services: How far have we come and how far do we still need to go? Ecosystem Services 28: 1-16. https://doi.org/10.1016/ j.ecoser.2017.09.008

- $\quad$ Crona B, Bodin Ö (2006) What you know is who you know? Communication patterns among resource users as a prerequisite for co-management. Resilience Alliance.

- Daniel TC, Muhar A, Arnberger A, Aznar O, Boyd JW, Chan KMA, Costanza R, Elmqvist T, Flint CG, Gobster PH, Gret-Regamey A, Lave R, Muhar S, Penker M, Ribe RG, Schauppenlehner T, Sikor T, Soloviy I, Spierenburg M, Taczanowska K, Tam J, der Dunk Av (2012) Contributions of cultural services to the ecosystem services agenda. Proceedings of the National Academy of Sciences 109 (23): 8812-8819. https:// doi.org/10.1073/pnas.1114773109

- Díaz-Reviriego I, Fernández-Llamazares Á, Howard PL, Molina JL, Reyes-García V (2016) Fishing in the Amazonian Forest: A Gendered Social Network Puzzle. Society \& Natural Resources 30 (6): 690-706. https://doi.org/10.1080/08941920.2016.1257079

- Díaz S, Demissew S, Carabias J, Joly C, Lonsdale M, Ash N, Larigauderie A, Adhikari JR, Arico S, Báldi A, Bartuska A, Baste IA, Bilgin A, Brondizio E, Chan KM, Figueroa VE, Duraiappah A, Fischer M, Hill R, Koetz T, Leadley P, Lyver P, Mace GM, Martin- 
Lopez B, Okumura M, Pacheco D, Pascual U, Pérez ES, Reyers B, Roth E, Saito O, Scholes RJ, Sharma N, Tallis H, Thaman R, Watson R, Yahara T, Hamid ZA, Akosim C, Al-Hafedh Y, Allahverdiyev R, Amankwah E, Asah ST, Asfaw Z, Bartus G, Brooks LA, Caillaux J, Dalle G, Darnaedi D, Driver A, Erpul G, Escobar-Eyzaguirre P, Failler P, Mokhtar Fouda AM, Fu B, Gundimeda H, Hashimoto S, Homer F, Lavorel S, Lichtenstein G, Mala WA, Mandivenyi W, Matczak P, Mbizvo C, Mehrdadi M, Metzger JP, Mikissa JB, Moller H, Mooney HA, Mumby P, Nagendra H, Nesshover C, OtengYeboah AA, Pataki G, Roué M, Rubis J, Schultz M, Smith P, Sumaila R, Takeuchi K, Thomas S, Verma M, Yeo-Chang Y, Zlatanova D (2015) The IPBES conceptual framework - connecting nature and people. Current Opinion in Environmental Sustainability 14: 1-16. https://doi.org/10.1016/i.cosust.2014.11.002

- Díaz S, Pascual U, Stenseke M, Martín-López B, Watson R, Molnár Z, Hill R, Chan KA, Baste I, Brauman K, Polasky S, Church A, Lonsdale M, Larigauderie A, Leadley P, van Oudenhoven AE, der Plaat Fv, Schröter M, Lavorel S, Aumeeruddy-Thomas Y, Bukvareva E, Davies K, Demissew S, Erpul G, Failler P, Guerra C, Hewitt C, Keune H, Lindley S, Shirayama $Y$ (2018) Assessing nature's contributions to people. Science 359 (6373): 270-272. https://doi.org/10.1126/science.aap8826

- $\quad$ Ernstson H, Sörlin S, Thomas Elmqvist (2009) Social Movements and Ecosystem Services-the Role of Social Network Structure in Protecting and Managing Urban Green Areas in Stockholm. Ecology And Society 13 (2). URL: https://doi.org/10.1002/pad.

- $\quad$ Fischer AP, Vance-Borland K, Jasny L, Grimm K, Charnley S (2016) A network approach to assessing social capacity for landscape planning: The case of fire-prone forests in Oregon, USA. Landscape and Urban Planning 147: 18-27. https:// doi.org/10.1016/i.landurbplan.2015.10.006

- $\quad$ Fish R, Church A, Winter M (2016) Conceptualising cultural ecosystem services: A novel framework for research and critical engagement. Ecosystem Services 21:

208-217. https://doi.org/10.1016/j.ecoser.2016.09.002

- $\quad$ Freeman L (1978) Centrality in social networks conceptual clarification. Social Networks 1 (3): 215-239. https://doi.org/10.1016/0378-8733(78)90021-7

- Freeman L (2004) The Development of Social Network Analysis: A Study in the Sociology of Science. Empirical Press, Vancouver.

- García-Amado LR, Pérez MR, Iniesta-Arandia I, Dahringer G, Reyes F, Barrasa S (2012) Building ties: social capital network analysis of a forest community in a biosphere reserve in Chiapas, Mexico. Ecology and Society 17 (3). https://doi.org/10.5751/ es-04855-170303

- Garcia-Martin M, Fagerholm N, Bieling C, Gounaridis D, Kizos T, Printsmann A, Müller M, Lieskovský J, Plieninger T (2017) Participatory mapping of landscape values in a Pan-European perspective. Landscape Ecology 32 (11): 2133-2150. https:// doi.org/10.1007/s10980-017-0531-x

- Goio I, Gios G, Pollini C (2008) The development of forest accounting in the province of Trento (Italy). Journal of Forest Economics 14 (3): 177-196. https://doi.org/10.1016/ j.jfe.2007.09.002

- Håkansson P, Witmer H (2015) Social Media and Trust - A Systematic Literature Review. Journal of Business and Economics 6 (3): 517-524. https://doi.org/10.15341/jbe (2155-7950)/03.06.2015/010

- Hauck J, Schmidt J, Werner A (2016) Using social network analysis to identify key stakeholders in agricultural biodiversity governance and related land-use decisions at 
regional and local level. Ecology and Society 21 (2). https://doi.org/10.5751/ es-08596-210249

- Hengeveld R, Heywood VH (1996) Global biodiversity assessment. Biodiversity Letters 3 (3): 115. https://doi.org/10.2307/2999726

- Hernández-Morcillo M, Plieninger T, Bieling C (2013) An empirical review of cultural ecosystem service indicators. Ecological Indicators 29: 434-444. https://doi.org/10.1016/ j.ecolind.2013.01.013

- Hopkins A (2011) Use of Network Centrality Measures to Explain Individual Levels of Herbal Remedy Cultural Competence among the Yucatec Maya in Tabi, Mexico. Field Methods 23 (3): 307-328. https://doi.org/10.1177/1525822x11399400

- Iceland C, Hanson C, Lewis C (2008) 'IDENTIFYING IMPORTANT ECOSYSTEM GOODS \& SERVICES IN PUGET SOUND Draft Summary of Interviews and Research for the Puget Sound Partnership Prepared by. World Resources Institute) Craig Hanson, Charles Iceland.

- IPBES (2013) Consideration of initial elements: Recognising indigenous and local knowledge and building synergies with science. IPBES/1/INF/5. Bonn, Germany. IPBES/1/INF/5.

- $\quad$ IPBES (2016) The Intergovernmental Platform on Biodiversity and Ecosystem Services (IPBES). Global Assessment https://doi.org/10.4324/9781315651095

- Jones K, Holland M, Naughton-Treves L, Morales M, Suarez L, Keenan K (2016) Forest conservation incentives and deforestation in the Ecuadorian Amazon. Environmental Conservation 44 (1): 56-65. https://doi.org/10.1017/s0376892916000308

- Kim Y, Choi T, Yan T, Dooley K (2010) Structural investigation of supply networks: A social network analysis approach. Journal of Operations Management 29 (3): 194-211. https://doi.org/10.1016/i.jom.2010.11.001

- Kocho-Schellenberg J, Berkes F (2015) Tracking the development of co-management: using network analysis in a case from the Canadian Arctic. Polar Record 51 (04): 422-431. https://doi.org/10.1017/s0032247414000436

- $\quad$ Kreitler J, Papenfus M, Byrd K, Labiosa W (2013) Interacting Coastal Based Ecosystem Services: Recreation and Water Quality in Puget Sound, WA. PLoS ONE 8 (2): e56670. https://doi.org/10.1371/journal.pone.0056670

- $\quad$ Krott M, Bader A, Schusser C, Devkota R, Maryudi A, Giessen L, Aurenhammer H (2014) Actor-centred power: The driving force in decentralised community based forest governance. Forest Policy and Economics 49: 34-42. https://doi.org/10.1016/ j.forpol.2013.04.012

- Maes J, Liekens I, Brown C (2018) Which questions drive the Mapping and Assessment of Ecosystems and their Services under Action 5 of the EU Biodiversity Strategy? One Ecosystem 3: e25309. https://doi.org/10.3897/oneeco.3.e25309

- Marín A, Berkes F (2010) Network approach for understanding small-scale fisheries governance: The case of the Chilean coastal co-management system. Marine Policy 34 (5): 851-858. https://doi.org/10.1016/j.marpol.2010.01.007

- Masterson VA, Stedman RC, Enqvist J, Tengö M, Giusti M, Wahl D, Svedin U (2017) The contribution of sense of place to social-ecological systems research: a review and research agenda. Ecology and Society 22 (1): 49. https://doi.org/10.5751/ es-08872-220149 
- MEA (2005) Environmental Degradation and Human Well-Being: Report of the Millennium Ecosystem Assessment. Population and Development Review 31 (2): 389-398. https://doi.org/10.1111/1.1728-4457.2005.00073.x

- Mertens F, Fillion M, Saint-Charles J, Mongeau P, Távora R, Sousa Passos CJ, Mergler D (2015) The role of strong-tie social networks in mediating food security of fish resources by a traditional riverine community in the Brazilian Amazon. Ecology and Society 20 (3): 18. https://doi.org/10.5751/es-07483-200318

- $\quad$ Mizruchi M (1994) Social network analysis: Recent achievements and current controversies. Acta Sociologica 37 (4): 329-343. https:// doi.org/10.1177/000169939403700403

- Newman L, Dale A (2006) Homophily and agency: Creating effective sustainable development networks. Environment, Development and Sustainability 9 (1): 79-90. https://doi.org/10.1007/s10668-005-9004-5

- $\quad$ Pascual U, Balvanera P, Díaz S, Pataki G, Roth E, Stenseke M, Watson RT, Dessane EB, Islar M, Kelemen E, Maris V, Quaas M, Subramanian SM, Wittmer H, Adlan A, Ahn S, Al-Hafedh YS, Amankwah E, Asah ST, Berry P, Bilgin A, Breslow SJ, Bullock C, Cáceres D, Daly-Hassen H, Figueroa E, Golden CD, Gómez-Baggethun E, GonzálezJiménez D, Houdet J, Keune H, Kumar R, Ma K, May PH, Mead A, O'Farrell P, Pandit R, Pengue W, Pichis-Madruga R, Popa F, Preston S, Pacheco-Balanza D, Saarikoski H, Strassburg BB, van den Belt M, Verma M, Wickson F, Yagi N (2017) Valuing nature's contributions to people: The IPBES approach. Current Opinion in Environmental Sustainability 26-27: 7-16. https://doi.org/10.1016/i.cosust.2016.12.006

- $\quad$ Pietri D, Stevenson T, Christie P (2015) The Coral Triangle Initiative and regional exchanges: Strengthening capacity through a regional learning network. Global Environmental Change 33: 165-176. https://doi.org/10.1016/i.gloenvcha.2015.05.005

- $\quad$ Plieninger T, Dijks S, Oteros-Rozas E, Bieling C (2013) Assessing, mapping, and quantifying cultural ecosystem services at community level. Land Use Policy 33 : 118-129. https://doi.org/10.1016/j.landusepol.2012.12.013

- $\quad$ Prell C, Reed M, Racin L, Hubacek K (2010) Competing structure, competing views: The role of formal and informal social structures in shaping stakeholder perceptions. Ecology and Society 15 (4): 34. https://doi.org/10.5751/es-03652-150434

- Raymond C, Fazey I, Reed M, Stringer L, Robinson G, Evely A (2010) Integrating local and scientific knowledge for environmental management. Journal of Environmental Management 91 (8): 1766-1777. https://doi.org/10.1016/j.jenvman.2010.03.023

- Reed M, Graves A, Dandy N, Posthumus H, Hubacek K, Morris J, Prell C, Quinn C, Stringer $L$ (2009) Who's in and why? A typology of stakeholder analysis methods for natural resource management. Journal of Environmental Management 90 (5): 1933-1949. https://doi.org/10.1016/i.jenvman.2009.01.001

- Rosa DL, Spyra M, Inostroza L (2016) Indicators of cultural ecosystem services for urban planning: A review. Ecological Indicators 61: 74-89. https://doi.org/10.1016/ j.ecolind.2015.04.028

- Ruef M, Aldrich H, Carter N (2003) The structure of founding teams: Homophily, strong ties, and isolation among U.S. entrepreneurs. American Sociological Review 68 (2): 195. https://doi.org/10.2307/1519766

- $\quad$ Satz D, Gould RK, Chan KMA, Guerry A, Norton B, Satterfield T, Halpern BS, Levine J, Woodside U, Hannahs N, Basurto X, Klain S (2013) The challenges of incorporating 
Cultural Ecosystem Services into environmental assessment. AMBIO 42 (6): 675-684. https://doi.org/10.1007/s13280-013-0386-6

- $\quad$ Sherchan W, Nepal S, Paris C (2013) A survey of trust in social networks. ACM Computing Surveys 45 (4): 1-33. https://doi.org/10.1145/2501654.2501661

- Shi Y, Yu X, Wang X, Zhang J (2013) The effects of stand structure on specific needle area in closed-canopy Chinese pine plantations. Journal of Forest Research 18 (6): 445-453. https://doi.org/10.1007/s10310-012-0372-z

- $\quad$ Small N, Munday M, Durance I (2017) The challenge of valuing ecosystem services that have no material benefits. Global Environmental Change 44: 57-67. https:// doi.org/10.1016/i.gloenvcha.2017.03.005

- $\quad$ Stevens K, Frank KA, Kramer DB (2015) Do social networks influence small-scale fishermen's enforcement of sea tenure? PLOS One 10 (3): e0121431. https:// doi.org/10.1371/journal.pone.0121431

- $\quad$ TEEB (2010) The economics of ecosystems and biodiversity: Ecological and economic foundations. Earthscan, London. teebweb.org.

- $\quad$ Tengberg A, Fredholm S, Eliasson I, Knez I, Saltzman K, Wetterberg O (2012) Cultural ecosystem services provided by landscapes: Assessment of heritage values and identity. Ecosystem Services 2: 14-26. https://doi.org/10.1016/i.ecoser.2012.07.006

- Tengö M, Brondizio E, Elmqvist T, Malmer P, Spierenburg M (2014) Connecting diverse knowledge systems for enhanced ecosystem governance: The Multiple Evidence Base Approach. AMBIO 43 (5): 579-591. https://doi.org/10.1007/s13280-014-0501-3

- Tengö M, Hill R, Malmer P, Raymond CM, Spierenburg M, Danielsen F, Elmqvist T, Folke C (2017) Weaving knowledge systems in IPBES, CBD and beyond-lessons learned for sustainability. Current Opinion in Environmental Sustainability 17-25. https:// doi.org/10.1016/i.cosust.2016.12.005

- $\quad$ Turner R, Polunin NC, Stead S (2014) Social networks and fishers' behavior: exploring the links between information flow and fishing success in the Northumberland lobster fishery. Ecology and Society 19 (2). https://doi.org/10.5751/es-06456-190238

- Uehara T, Sakurai R, Tsuge T (2018) Cultivating relational values and sustaining socioecological production landscapes through ocean literacy: a study on Satoumi. Environment, Development and Sustainability https://doi.org/10.1007/ s10668-018-0226-8

- $\quad$ Ungaro F, Häfner K, Zasada I, Piorr A (2016) Mapping cultural ecosystem services: Connecting visual landscape quality to cost estimations for enhanced services provision. Land Use Policy 54: 399-412. https://doi.org/10.1016/

j.landusepol.2016.02.007

- Wellman B, Frank K (2001) Network capital in a multi-level world: Getting support from a personal communities. Social Capital: Theory and Research 233-273.

- Whyte KP, Brewer JP, Johnson JT (2015) Weaving Indigenous science, protocols and sustainability science. Sustainability Science 11 (1): 25-32. https://doi.org/10.1007/ s11625-015-0296-6

- $\quad$ Xerez R (2013) How Do the Evolution and Innovation of Social Network Analysis Matter to Computer Science and Communications? Social Networking 02 (03): 147-151. https://doi.org/10.4236/sn.2013.23013

- Yamaki K (2017) Applying social network analysis to stakeholder analysis in Japan's natural resource governance: two endangered species conservation activity cases. 
Journal of Forest Research 22 (2): 83-90. https://

doi.org/10.1080/13416979.2017.1279706

- Zimmerer KS (2014) Conserving agrobiodiversity amid global change, migration, and nontraditional livelihood networks: the dynamic uses of cultural landscape knowledge. Ecology and Society 19 (2): 1. https://doi.org/10.5751/es-06316-190201

\section{Supplementary material}

Suppl. material 1: Selected publications for this review and their interrelationship between Social network aspects and cultural ecosystem services. doi

Authors: Francisca Mutwa Kilonzi and Takahiro Ota

Data type: Review search results

Brief description: Selected publications for this review and their interrelationship between Social network aspects and cultural ecosystem services.

Download file $(99.66 \mathrm{~kb})$ 